\title{
Ignition and Burning of Fibreboard Exposed to Transient Irradiation
}

\author{
Izabella Vermesi (D), Bureau Veritas, London, UK \\ Franz Richter, Department of Mechanical Engineering, Imperial College \\ London, South Kensington Campus, London SW7 2AZ, UK; Department \\ of Mechanical Engineering, University of California, Berkeley, Berkeley, \\ $U S A$ \\ Marcos Chaos, Energetic Materials Center, Lawrence Livermore National \\ Laboratory, Livermore, USA \\ Guillermo Rein (D), Department of Mechanical Engineering, Imperial College \\ London, South Kensington Campus, London SW7 2AZ, UK
}

Received: 13 November 2017/Accepted: 8 June 2020

\begin{abstract}
Natural materials like wood are increasingly used in the construction industry, making the understanding of their ignition and burning behaviour in fires crucial. The state of the art of wood flammability is based mostly on studies at constant heating. However, accidental fires are better represented by transient heating. Here, we study the piloted ignition and burning of medium density fibreboard (MDF) under transient irradiation. Experiments are conducted in a Fire Propagation Apparatus under parabolic heat flux pulses with peak irradiation ranging from 30 to $40 \mathrm{~kW} / \mathrm{m}^{2}$ and time-to-peak irradiation from 160 to $480 \mathrm{~s}$. The experimental results reveal that the critical conditions for ignition of fibreboard vary over wide ranges: mass flux between 4.9 to $7.4 \mathrm{~g} / \mathrm{m}^{2}$-s, surface temperature between 276 to $298^{\circ} \mathrm{C}$, and heat flux between 29 to $40 \mathrm{~kW} / \mathrm{m}^{2}$. Flameout conditions are studied as well, with observations of when it leads either to extinction or to smouldering combustion. We explored the experiments further with a one-dimensional pyrolysis model in Gpyro and show that predictions are accurate. Assuming a non-uniform density profile (a realistic assumption) improves the predictions in comparison to a uniform density profile by increasing the mass loss rate by $12 \%$, decreasing the temperatures by $45 \%$, and increasing the ignition time by $20 \mathrm{~s}$. These results further support previous findings that a single critical condition for igntion or flameout established under constant irradiation does not hold under transient irradiation which indicates that ignition and extinction theories need improvements.
\end{abstract}

Keywords: Pyrolysis, Ignition, Wood, Experiment, Fire

\footnotetext{
* Correspondence should be addressed to: Guillermo Rein, E-mail: g.rein@imperial.ac.uk
} 


\section{Introduction}

Fiberboard is an engineered wood product that is widely used in the built environment, furniture applications, and as insulation material [1]. It is manufactured by binding wood fibers with wax or resin under high temperature and pressure conditions [2]. Its thermal properties and fire behavior differ from the ones of natural wood and timber, which warrants the separate investigation of fiberboard. Accidental fires are a major risk for all natural materials making it essential to have a good understanding of their behaviour in a fire.

The ignition and burning of wood has been studied previously both experimentally and numerically. Emmons and Atreya [3] were the first to collect and summarize previous works on ignition in an attempt to move the focus away from empirical correlations and into understanding the physical processes that occur when wood is exposed to fire. That work was later extend to study the flame spread over wood [4]. Atreya and Abu-Zaid [5] studied experimentally the effect of environmental variables on the piloted ignition of wood. They found that ignition time is proportional to the moisture content and air velocity, and inversely proportional to irradiation and oxygen concentration. Only at low irradiation, does moisture content not influence piloted ignition. Boonmee and Quintiere studied the smouldering ignition of wood $[6,7]$ in a cone heater and found that smouldering ignition occurs at lower heat fluxes than flaming ignition. Numerical models include Spearpoint and Quintiere' [8] as well as Park et al. [9] who developed one-dimensional models of smouldering and pyrolysis of wood respectively. The former focused on the burning rate and found that it is influenced by the species of wood, while the latter looked at kinetics and proposed a chemical reaction scheme that is able to predict the experimental measurements. Recently, Richter et al. [10] showed that the variability in the burning rate of wood stems from the natural variation in the material properties rather than the chemical composition of wood. In other words, previous studies have largely focused on studying ignition to identify a single ignition criteria (temperature, mass loss rate, or heat flux). The extinction of wood has been treated in a similar manner to identify either a critical heat flux [11] or a critical mass loss rate [12].

The behaviour of fibreboard has been less studied than natural wood. Wasan et al. $[13,14]$ reported temperature profiles and mass loss rate of medium density fiberboard (MDF) of different moisture contents. They confirmed for fibreboard that moisture delays ignition as previously found for wood. Li and co-workers have a number of publications dealing with the thermo-physical and kinetic parameters of MDF. In [15], they measured the specific heat capacity, thermal conductivity and density of MDF and its char, while in [16], the kinetic parameters and heat of pyrolysis were investigated using TGA and DSC experiments. The kinetic scheme was optimized via a genetic algorithm in [17] to obtain a set of kinetic parameters, and the flame irradiation was measured in [18]. Huang et al. [19] numerically investigated the influence of kinetic scheme complexity, shrinkage, transient flame irradiation and vertical density profile on mass loss rate. Zhao et al. [20] combined numerical and experimental results to suggest the need to account for in-depth absorption in the modelling of the pyrolysis of MDF, which 
is in contrast to previous experimental measurements for wood that show the insignificance of in-depth absorption [21]. Further work is required on this topic; however, the present authors consider the experimental work of Girods et al. [21] as compelling evidence for the lack of influence of in-depth radiation on the mass loss rate of wood and fibreboard.

All previous studies used a constant irradiation boundary condition for simplicity. While this simplicity is convenient, its case is singular and does not reflect a scenario of an accidental fire. Transient irradiation is a more comprehensive and realistic case for accidental fire, as nonlinear heat transfer effects challenge the general validity of findings and criteria from studies under constant irradiation. In other words, transient irradiation is a generalised version of constant irradiation, making it essential to study ignition under both constant and transient irradiation. Currently, there is only one study on fibreboard under transient irradiation [22], and even for wood there are only two [23, 24]. Agarwal et al. [22] used transient irradiation in different forms (constant irradiation, step-change in irradiation, linearly increasing irradiation) to propose a set of material and kinetic properties for fibreboard obtained through inverse modelling, but did not study the effect of these conditions on ignition or extinction. A few works [25-29] have investigated synthetic polymers under transient conditions and the applicability of ignition criteria to them. They generally disagree on the outcome with some favouring the applicability of a single ignition criteria (e.g., [25]) while others favour multiple ignition criteria (e.g., [29]).

Here we aim to investigate the effect of density on the ignition behaviour of MDF under transient irradiation at two moisture contents and test the applicability of a single ignition criteria to our study. There is growing evidence of the importance of the density profile in MDF [13-19, 22] but its significance remains unknown. Furthermore, it has not been explored for transient irradiation. At the same time, several studies (e.g., $[4,5,30]$ have shown the influence of moisture content on ignition under constant irradiation, and we will test computationally here if our findings hold across different moisture contents. In other words, This paper will show whether the theoretical framework of natural wood also holds for fibreboard. To this end, we will use a model previously described and validated in a work-in-progress publication [31] and apply it to unravel the effect of density on ignition.

\section{Experimental Methods}

The experiments used in this work were conducted in the FM Global Fire Propagation Apparatus (FPA). These experiments were previously described in [31]. 18$\mathrm{mm}$ thick MDF samples were placed onto aluminium plates of $25 \mathrm{~mm}$ thickness for well-defined heat losses [32]. The back-side of the aluminium plate and the sides of the sample were covered with Cotronics insulation to minimize the lateral heat losses. The surface temperature was read using an infrared pyrometer and the mass loss was recorded using a load cell. Details regarding the pyrometer measurements and their validation can be found elsewhere [33, 34]. A wireless thermo- 
couple was inserted in the aluminium plate to measure its temperature and determine a heat loss boundary condition [32]. The use of a wireless thermocouple is novel and allows for the simultaneous measurement of mass loss (unachievable with wired thermocouples) and temperature. The samples had a measured bulk density of $605 \mathrm{~kg} / \mathrm{m}^{3}$ and a moisture content of $7 \%$. This moisture content was achieved by drying the samples and then conditioning them for $24 \mathrm{~h}$ at $50 \% \mathrm{RH}$, which yields an estimated moisture content of $6 \%$ to $7 \%$ as described in [35]. An ethylene-air pilot was placed $10 \mathrm{~mm}$ above the sample surface and $10 \mathrm{~mm}$ away from the perimeter of the specimen. Each experiment was repeated three times.

Parabolic irradiation curves imitate both the growth and the decay of irradiation in a fire. Seven different parabolas are used, as shown in Fig. 1, with the addition of a constant irradiation scenario of $20 \mathrm{~kW} / \mathrm{m}^{2}$, which was carried out to validate the setup and to provide a link to literature. The curves were verified experimentally in [31]. The two varying parameters of the parabolic curves are the peak irradiation and the time to reach this peak. Four times-to-peak were used in the investigation, ranging from $160 \mathrm{~s}$ to $480 \mathrm{~s}$ and the peak irradiations are $30 \mathrm{~kW} / \mathrm{m}^{2}, 35 \mathrm{~kW} / \mathrm{m}^{2}$ and $40 \mathrm{~kW} / \mathrm{m}^{2}$. These curves are chosen to represent a wide range of heating scenarios from slow to fast heating and from low to high intensity heating. The peak value of each irradiation curve exceeds that of the critical irradiation for smouldering ignition $\left(10 \mathrm{~kW} / \mathrm{m}^{2}\right)$ [7]. Details about the peak irradiation and time to peak, which characterize the parabolas, are summarized in Table S1 of the Supplementary Material. Time to ignition was observed visually and it varies from $161 \mathrm{~s}$ in Scenario $4 \mathrm{~s}$ to $408 \mathrm{~s}$ in Scenario 0 (constant irradiation), with an error of roughly $1 \mathrm{~s}$ based on previous in-house experience. As this error is below $1 \%$, no error bars for ignition and flame-out time are given in the graphs. The errors in the experimental measurement are estimated to be around

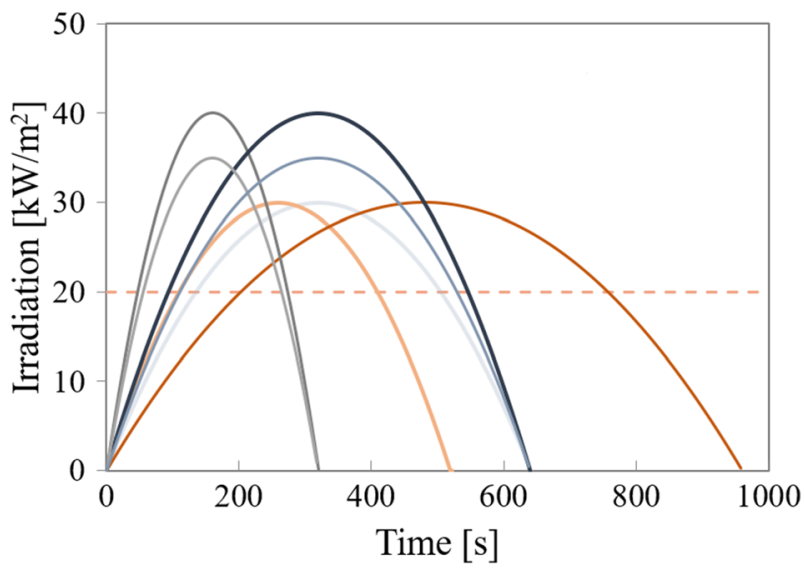

Figure 1. Summary of the seven parabolic irradiation curves (solid lines) and the one constant heat flux (dashed line) used in the experiments. The constant heat flux is used for comparison. A full list of all scenarios is given in Table $\mathbf{S 1}$ of the Supplementary Materials. 
$5 \mathrm{~K}$ for the temperatures [33] and an error of $1 \mathrm{~g} / \mathrm{m}^{2}$-s in the mass loss rate based on in-house experiments with the same experimental set-up which is close to the errors calculated by [36].

\section{Computational Model}

We previously described and preliminarily validated the computational model in [31] and details for the validation can be found there.The setup and sample were modelled using the open-source pyrolysis code Gpyro [37]. The governing equations are listed as follows: condensed-phase mass conservation (Eq. 1), species conservation (Eq. 2) and the energy equation (Eq. 3). Thermal equilibrium between the condensed-phase and the gas-phase is assumed. The shrinkage of the sample was taken into account following [19], with further information therein and the validation of the shrinkage formulation found in [37]. As shown in the literature [21, 34, 38], in-depth radiation is not important for wood and, therefore, in-depth radiation was not taken into account. The reaction rate is expressed by the Arrhenius equation (Eq. 4).

$$
\frac{\partial \bar{\rho}}{\partial t}=-\dot{\omega}_{f g}^{\prime \prime \prime}
$$

were $\rho$ is the density, $t$ is time, and $\dot{\omega}_{f g}^{\prime \prime \prime}$ is rate of formation of gases. The overbar represents the respective mass or volume avarage of quantity, for details see [37].

$$
\frac{\partial\left(\bar{\rho} Y_{i}\right)}{\partial t}=-\dot{\omega}_{d i}^{\prime \prime \prime}
$$

where $Y_{i}$ is the mass fraction of species $i$, and $\dot{\omega}_{d i}^{\prime \prime \prime}$ the destruction rate of species $i$.

$$
\frac{\partial(\bar{\rho} \bar{h})}{\partial t}=\frac{\partial}{\partial z}\left(\bar{k} \frac{\partial T}{\partial z}\right)+\sum_{i=1}^{K}\left(-\dot{\omega}_{d i}^{\prime \prime \prime}\right) \Delta H_{s}
$$

where $h$ is the enthalpy, $z$ the spatial dimension (depth), $k$ the thermal conductivity, $T$ the temperature and $\Delta H_{s}$ is the heat of pyrolysis.

$$
\dot{\omega}_{d i}^{\prime \prime \prime}=\bar{\rho} Y_{A, i} A_{i} \exp \left(-E_{i} / R T\right)
$$

where $A$ is the pre-exponential factor, $E$ the activation energy, and $R$ the universal gas constant. Furthermore, the rate of formation of gases is defined as

$$
\dot{\omega}_{f g}^{\prime \prime \prime}=\sum_{i} \dot{\omega}_{d i}^{\prime \prime \prime}
$$

The domain for the one-dimensional model of the experiments is shown in Fig. 2 and resembles the experiment with a free top surface at $z=0$, an adiabatic bot- 
tom surface at $z=L$ (Eq. 7), and no heat losses to the sides. The top surface $(z=0)$ is exposed to the irradiation and has convective and radiative losses (Eq. 6). The convection coefficient was taken as $20 \mathrm{~W} / \mathrm{m}^{2}-\mathrm{K}$ [24]. Keeping a balance between accuracy and simulation time, the final values of the domain parameters are a cell size of $0.01 \mathrm{~mm}$ and a time step of $0.1 \mathrm{~s}$ based on the grid independence study of a similar model by [29].

$$
z=0 \quad-\bar{k} \frac{\partial T(0)}{\partial z}=\bar{\varepsilon} \dot{q}_{e}^{\prime \prime}-h_{c}\left(T(0)-T_{\infty}(0)\right)-\bar{\varepsilon} \sigma\left(T(0)^{4}-T_{\infty}(0)^{4}\right)
$$

where $\varepsilon$ is the emissivity, $\dot{q}_{e}^{\prime \prime}$ the external heat flux, $h_{c}$ the convective heat transfer coefficient, $T_{\infty}$ the initial temperature and $\sigma$ the Stefan-Boltzman constant. The external heat flux is temperature dependent as shown in Fig. 1. The emissivity and heat transfer coefficient were assumed constant as the heat transfer coefficient is only expected to vary by $20 \%$ and the sensitivity of the char depth predicted by a pyrolysis model to heat transfer coefficient is low [39], the emissivity of char is relatively constant [34], and the emissivity of wood is relatively constant up to around $600 \mathrm{~K}$ (prior to ignition) [34].

$$
z=L \quad-k_{A T} \frac{\partial T(L)}{\partial z}=h_{c}(T(0)-295 \mathrm{~K})
$$

Atreya [4] showed that finite rate kinetics are required to capture ignition. Following him we estimate the chemical timescale to be larger (58 $\mathrm{min}$ ) [40] than the largest timescale of the pulse $(16 \mathrm{~min})$. The chemical reaction scheme and parameter values were proposed by $\mathrm{Li}$ et al. [17] for MDF. A drying step was added here. The values of the drying step parameters were chosen from Lautenberger et al.

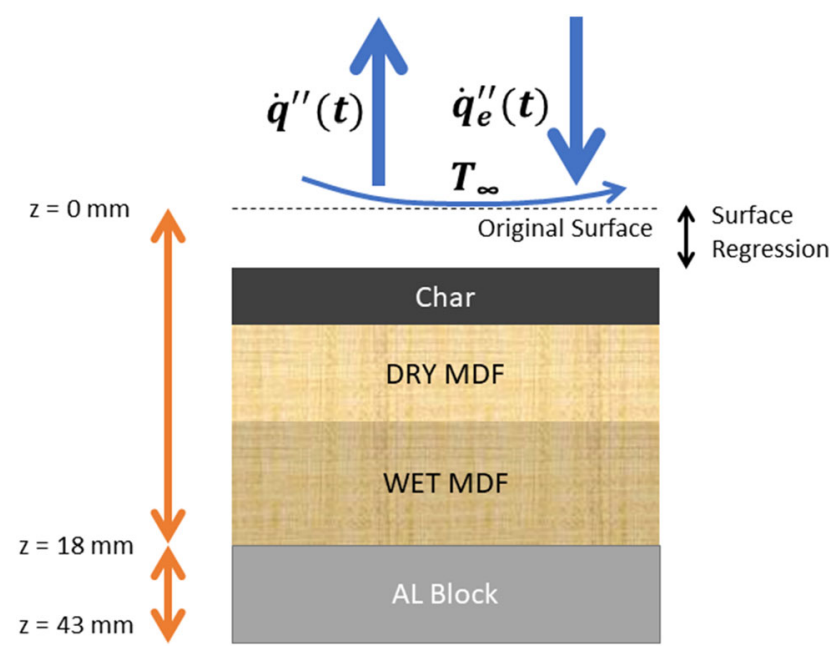

Figure 2. Sketch of the computational domain and illustration of the different stages of the pyrolysis of MDF including shrinkage. 
[41]. Equation 8 only holds for the three organic components of fibreboard (cellulose, hemicellulose, lignin) while we assume that the resin does not undergo drying. The values for the pre-exponential factor, activation energy, heat of pyrolysis, reaction order, and solid yields are summarized in Table 1.

$$
\begin{aligned}
& \text { wet component } \rightarrow \text { dry component }+ \text { water vapour } \quad \text { (drying) } \\
& \text { hemicellulose } \rightarrow \text { char }+ \text { pyrolyzate } \\
& \text { cellulose } \rightarrow \text { char }+ \text { pyrolyzate }
\end{aligned}
$$$$
\text { lignin } \rightarrow \text { char }+ \text { pyrolyzate }
$$

$$
\text { resin } \rightarrow \text { char }+ \text { pyrolyzate }
$$

The thermal properties used in the simulations are listed in Table 2 for MDF and Table 3 for the aluminium block [42]. The bulk density of MDF was measured prior to the experiment. All other parameters were taken from the literature. No parameter fittings were used. After ignition, a constant radiative flux of $30 \mathrm{~kW} / \mathrm{m}^{2}$ was applied to represent the flame irradiation following the work of Huang et al. [19].

As mentioned previously, MDF does not have a homogeneous density profile because of the pressing process through which it is obtained. Therefore, a nonuniform density (NUD) profile was calculated using Eq. 13, taken from Agarwal et al. [22] (Fig. 3).

\section{Table 1}

Modelling Values for Kinetic Constants for Each Reaction: Drying Kinetics from [4 1 ], MDF Kinetics from [1 9 ]

\begin{tabular}{lcccccc}
\hline Kinetic constants Parameter $\mid$ Equation & 8 & 9 & 10 & 11 & 12 & Units \\
\hline Pre-exponential factor log A & 3.63 & 12.9 & 13.6 & 16.3 & 13.6 & $\log \left(\mathrm{s}^{-1}\right)$ \\
Activation energy E & 43.8 & 165 & 189 & 238 & 149 & $\mathrm{~kJ} / \mathrm{mol}$ \\
Heat of pyrolysis $\Delta H$ & 2410 & 150 & 150 & 150 & 1100 & $\mathrm{~kJ} / \mathrm{kg}$ \\
Reaction order n & 0.99 & 2.4 & 0.84 & 10.4 & 4.7 & - \\
Solid yield $v$ & 0.93 & 0.115 & 0.248 & 0.272 & 0.116 & - \\
Dry mass fraction $Y$ & 0.07 & 0.317 & 0.408 & 0.18 & 0.099 & - \\
\hline
\end{tabular}


Table 2

Modelling Parameters: Temperature Dependent Properties for MDF and Char in the form of $X(T)=X_{0}\left(\frac{T}{300 K}\right)^{a}$

\begin{tabular}{lllll}
\hline Temperature dependent properties Property & Value $X_{0}$ & Exponent value $a$ & Units & References \\
\hline Thermal conductivity $k$ & 0.12 & 0.49 & $\mathrm{~W} / \mathrm{mK}$ & {$[15]$} \\
Density $\rho$ & 605 & - & $\mathrm{kg} / \mathrm{m}^{3}$ & Measured \\
Specific heat capacity $c_{p}$ & 1473 & 0.78 & $\mathrm{~J} / \mathrm{kgK}$ & {$[15]$} \\
Surface emissivity of MDF $\epsilon$ & 0.75 & - & & {$[41]$} \\
Thermal conductivity of char $k_{\text {char }}$ & 0.1 & 1.42 & $\mathrm{~W} / \mathrm{mK}$ & {$[15]$} \\
Density of char $\rho_{\text {char }}$ & 190 & - & $\mathrm{kg} / \mathrm{m}^{3}$ & {$[19]$} \\
Specific heat capacity of char $c_{p, \text { char }}$ & 680 & 0.49 & $\mathrm{~J} / \mathrm{kgK}$ & {$[15]$} \\
Surface emissivity of char $\epsilon_{\text {char }}$ & 0.96 & - & & {$[19]$} \\
\hline
\end{tabular}

\section{Table 3}

\section{Modelling Parameters: Properties of Aluminium Block (from [42])}

\begin{tabular}{lrc}
\hline Properties of aluminium Property & Value & Units \\
\hline Thermal Conductivity $k_{A l}$ & 167 & $\mathrm{~W} / \mathrm{mK}$ \\
Density $\rho_{A l}$ & 2700 & $\mathrm{~kg} / \mathrm{m}^{3}$ \\
Specific heat capacity $c_{p, A l}$ & 896 & $\mathrm{~J} / \mathrm{kgK}$ \\
Emissivity of aluminium $\epsilon$ & 1 & - \\
\hline
\end{tabular}

$$
\rho_{0}(z)=\bar{\rho}\left\{1+\frac{1-\xi}{2+\xi}\left[1-12\left(\frac{z}{L_{0}}-\frac{1}{2}\right)\right]\right\}
$$

where $\bar{\rho}$ is the bulk (i.e., mean) density $\left(605 \mathrm{~kg} / \mathrm{m}^{3}\right.$ in this case), and $\xi$ is the ratio of the maximum density (occurring at the surface) to the minimum density (occurring at $z=\frac{L_{0}}{2}$ ) and has a value of $\xi=1.61$ [22]. $L_{0}$ is the fibreboard's thickness (i.e. $18 \mathrm{~mm}$ )

The density of char was assumed to be uniform and independent of temperature based on the results in [18]. A sensitivity analysis was run in order to find the appropriate discretization of the density profile - as Gpyro required discretization of the curve-with results discussed in Sect. 4 below. Thus going from coarse to fine, we implemented four levels of discretization (Fig. 3): (1) 3 layers of $9 \mathrm{~mm}$, (2) 6 layers of $3 \mathrm{~mm}$, (3) 9 layers of $2 \mathrm{~mm}$, and (4) 18 layers of $1 \mathrm{~mm}$. 


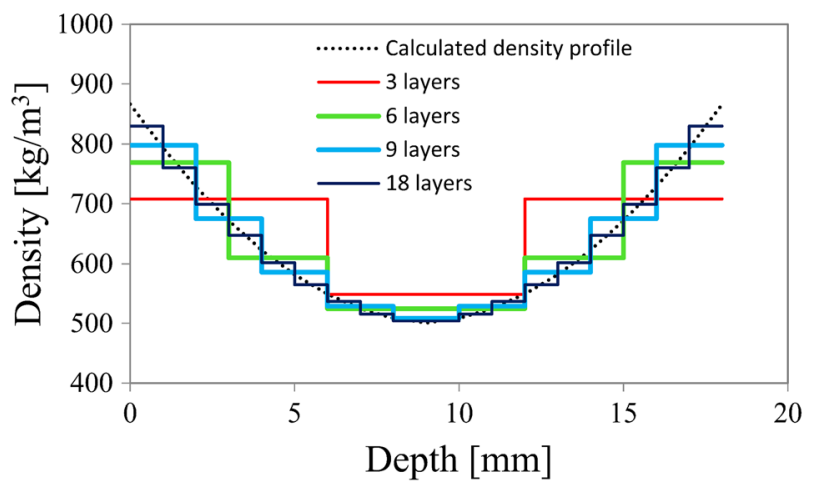

Figure 3. Density profile discretization: the implementation of the actual density profile (shown in a dotted line), which was calculated based on Eq. 13 , was performed in four levels. From a simple 3 layers of $6 \mathrm{~mm}$ (1), the discretization becomes finer to 6 layers of $3 \mathrm{~mm}$ (2), 9 layers of $2 \mathrm{~mm}$ (3), and finally 18 layers of $1 \mathrm{~mm}$ (4).

\section{Results and Discussion}

\subsection{Experimental results for the Ignition and Extinction of MDF}

This section considers pilot ignition and flameout as a function of the irradiation curve, and suggests that ignition criteria under transient irradiation are similar to those under constant irradiation. Figure 4 summarizes the values of mass loss rate (MLR) and surface temperature at ignition for all 8 scenarios. In the experiments, MLR at ignition ranges between $5 \mathrm{~g} / \mathrm{m}^{2}$-s and $8 \mathrm{~g} / \mathrm{m}^{2}$-s. The MLR is higher than the literature values of similar materials, which are around $3.4 \mathrm{~g} / \mathrm{m}^{2}-\mathrm{s}$ for plywood [43] and $2 \mathrm{~g} / \mathrm{m}^{2}$-s for poplar [44] under constant irradiation. Surface temperatures at ignition are close to $300^{\circ} \mathrm{C}$ for the majority of cases, with the exception being the parabolic flux with a time to peak of $260 \mathrm{~s}$ and a peak irradiation of $30 \mathrm{~kW} /$ $\mathrm{m}^{2}$. The literature values for ignition temperatures for wood are between $300^{\circ} \mathrm{C}$ and $350^{\circ} \mathrm{C}$ [45] under constant irradiation. This comparison would suggest that a critical mass loss rate is a sufficient ignition criteria for MDF. However, in Scenario 3, see Fig. 4, the mass loss rate exceeds the critical mass loss rate but the sample did not ignite at the $200 \mathrm{~s}$ mark. This experiment supports previous studies that found that one ignition criteria is insufficient to predict the ignition of wood [24] and PMMA [29]. The applicability of a multi-threshold for ignition could not be tested further in this study, as ignition occurred in all experiments.

It is interesting to see when ignition and flameout occurred under different parabolic irradiations, as shown in Fig. 5. For comparison, the time to ignition for constant irradiation is $408 \mathrm{~s}$ and flameout occured after $720 \mathrm{~s}$. In the cases with a lowest time to peak heat flux (160 s), flameout coincides with the end of the parabolic flux, which shows that the flame is not able to sustain itself without additional heating. For the cases with times-to-peak of $260 \mathrm{~s}$ to $320 \mathrm{~s}$, ignition occurs before the peak heat flux is reached and flameout happens before the parabolic flux ends. For the scenarios with time to peak heat flux of $480 \mathrm{~s}$ to peak, 

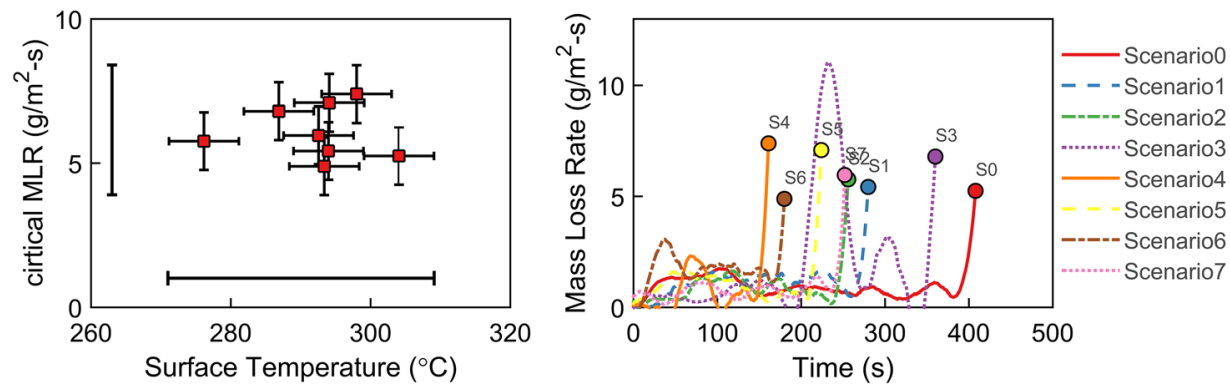

\section{Figure 4. (Left) experimental measurements of MLR and surface temperature at ignition are shown. (Right) the evolution of the mass loss rate prior to ignition is shown.}

ignition occurs $120 \mathrm{~s}$ before the peak and lasts for $60 \mathrm{~s}$. All cases, therefore, show that subjecting MDF to parabolic heating scenarios does not cause sustained flaming after heating is removed or insufficient heating is applied, as has previously been shown for wood [11]. At flameout, the conditions varied widely with mass loss rates between $1.4 \mathrm{~g} / \mathrm{m}^{2}-\mathrm{s}$ and $17 \mathrm{~g} / \mathrm{m}^{2}$-s, heat fluxes between $0 \mathrm{~kW} / \mathrm{m}^{2}$ and $29 \mathrm{~kW} / \mathrm{m}^{2}$, and surface temperatures between $520^{\circ} \mathrm{C}$ and $670^{\circ} \mathrm{C}$ (see Table S2 in the Supplementary Material). We observed three different flameout conditions, shown in Fig. 6: extinction, transition to unsustained smouldering, and transition to sustained smouldering. The first (extinction) is when flameout occurs close to the removal of the heat flux (Scenarios 4 and 6) and the mass loss rate rapidly decreases once flaming ceases reaching a value of zero when the heat flux is removed. The second (flaming to unsustained smouldering) is when flameout occurs earlier during the experiment. The sample then transitions from flaming to unsustained smouldering where the burning rate stays relatively constant until the heat flux is removed and the mass loss rate becomes zero (Scenario 3). The third (flaming to sustained smouldering) similarly occurs when flameout takes place early in the experiments. The sample transitions to sustained smouldering where the burning rate gradually decreases, but burning continues after the external heat flux has ceased (Scenarios 2, 3, 5, and 7). The transition of flaming to smouldering and the subsequent continuation of smouldering presents a significant risk if MDF is used in buildings as it offers the potential for re-ignition of a flaming fire.

\subsection{Influence of Non-uniform Density at Two Different Moisture Contents}

The significant influence of drying on the modeled temperature and MLR profiles using a uniform density distribution is shown in Fig. 7 for both constant and transient irradiation. Additional scenarios are shown in the Supplementary Material to illustrate different behaviors when varying time to peak irradiation, magnitude of peak irradiation, and discretization. For the constant irradiation scenario, the drying step reduces the predicted surface temperature by up to $56^{\circ} \mathrm{C}$. For the transient scenarios drying only reduces the predicted surface temperature by a maximum of $29^{\circ} \mathrm{C}$. In all cases, the model over-predicts the initial increase in sur- 

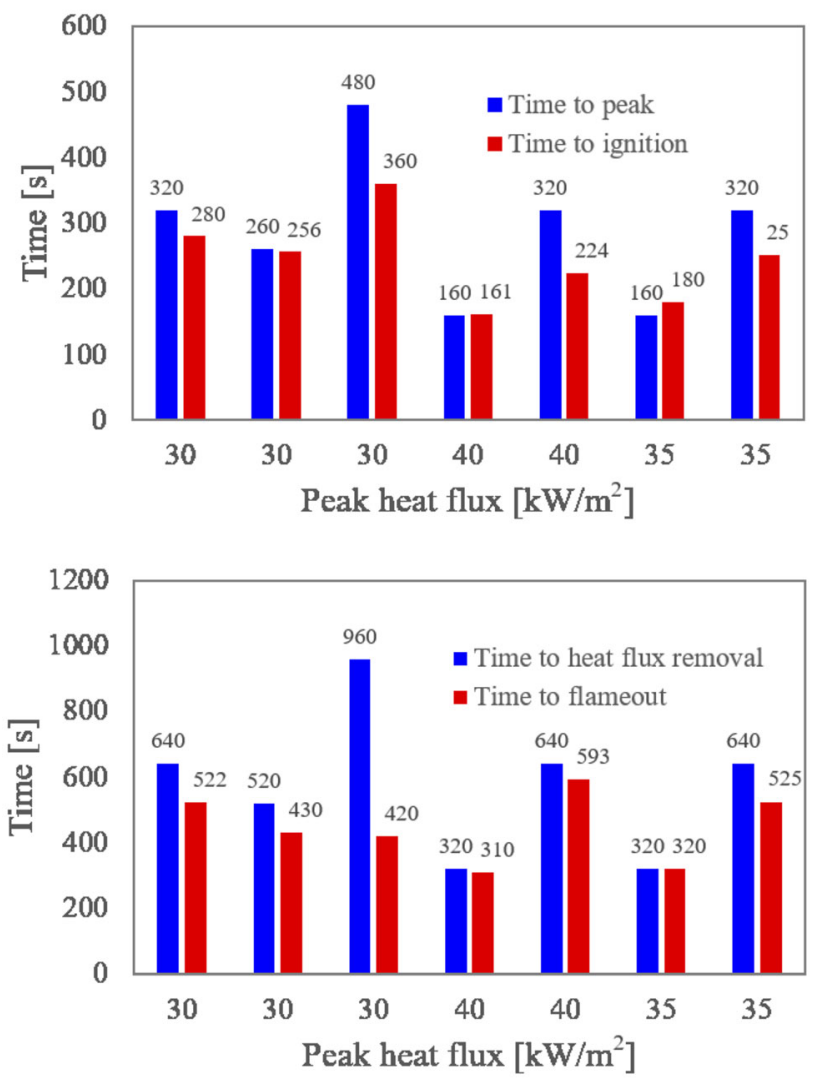

Figure 5. Comparison between the time to peak versus the time to ignition (top), and time to the end of irradiation versus the time to flameout (bottom) for all transient irradiation scenarios (measurements).

face temperature and under-predicts the peak immediately after ignition. Furthermore, the average error between experimental and predicted surface temperature is small for constant irradiation ( $8 \%$ ), but large $(44 \%)$ for transient irradiation. The reason for these discrepancies is likely the lack of oxidative reactions in the chemical kinetics, making the model unable to capture the smoldering behaviour of fibreboard [9].

Adding drying allows for better capture of the initial MLR behavior ( $t \leq 410 \mathrm{~s}$ in Fig. $7 \mathrm{~b}$ and $t \leq 280 \mathrm{~s}$ in Fig. 7d) during which moisture evaporates. Drying decreases the peak MLR for constant irradiation (16\% in Fig. $7 \mathrm{~b}$ as well as Figs. S2 and S3) and increases it for transient irradiation (10\% in Fig. 7d). In spite of this, the model underpredicts the peak MLR by $14 \mathrm{~g} / \mathrm{m}^{2}-\mathrm{s}$ compared to the experimental measurement. Likely, the quantitative disagreement in this paper stems from an insufficient representation of the gas-phase combustion, as the model predicts the mass loss rate prior to ignition and after flameout with an 

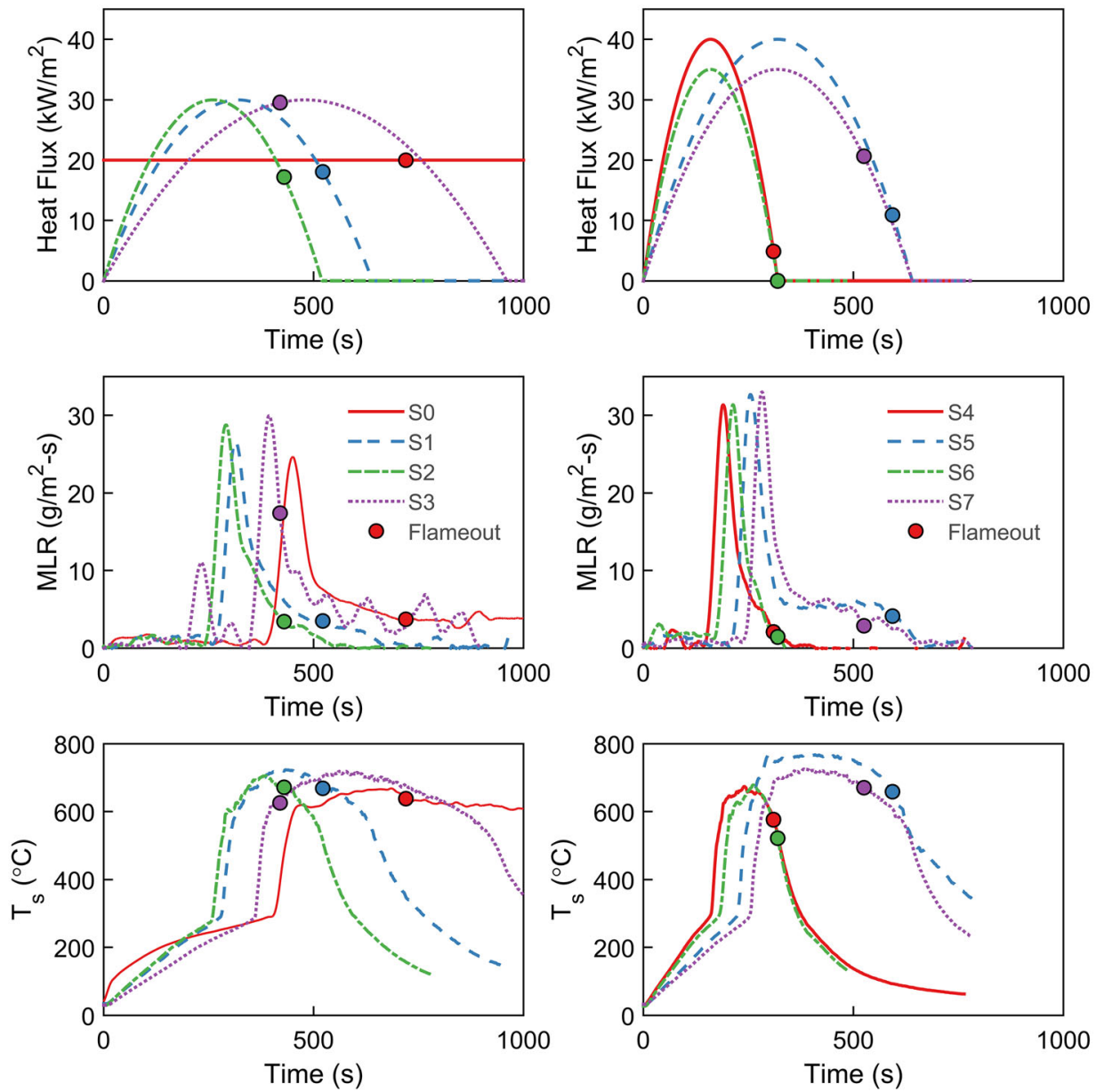

Figure 6. An overview of the surface temperature and mass loss rate evolution of each scenario with the flameout indicated. The first row shows the heat flux, the second row the mass loss rate, and the third row the surface temperature.

average error of roughly $1 \mathrm{~g} / \mathrm{m}^{2}$-s. Here, we simplified the heat transfer from the gas-phase combustion to the solid as a constant heat flux, while in reality it will vary depending on the flame and its position. As a result, we can consider drying to be an important mechanism to model when assuming a homogeneous density throughout the sample as it changes temperatures and mass loss rates by roughly $10 \%$ to $15 \%$ as argued above.

Addition of a drying step in the model lowered the predicted in-depth temperatures through the solid, as the additional drying front consumes heat (Fig. 7a, c). A lower temperature results in delayed ignition. These results, however, only hold for a uniform density profile in the solid. Once we simulate one of the four dis- 

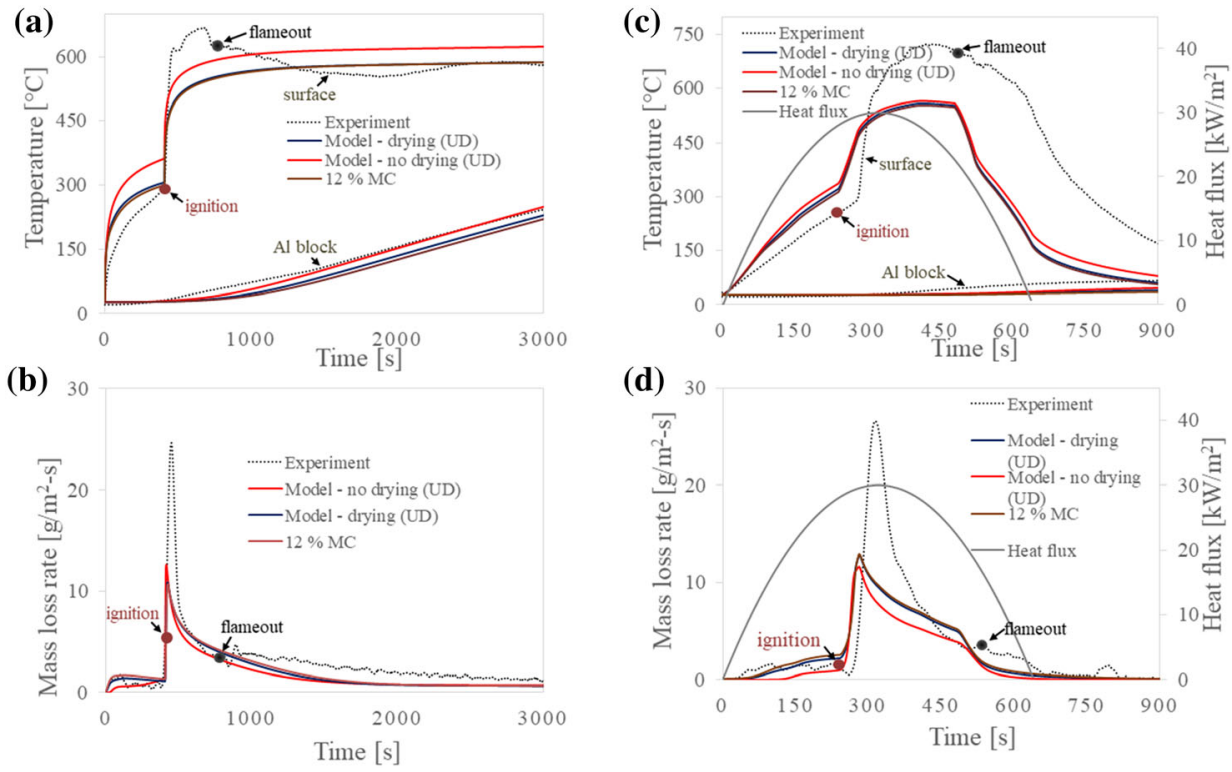

\section{Figure 7. Influence of drying Left: Temperature (a) and MLR (b) experiments (dotted lines) and model predictions (solid lines) for the scenario with constant irradiation of $20 \mathrm{~kW} / \mathrm{m}^{2}$. Right: Temperature (c) and MLR (d) experiments (dotted lines) and model predictions (solid lines) for transient irradiation Scenario 1 (30 $\mathrm{kW} / \mathrm{m}^{2}$ peak and 320 s time to peak; heat flux is shown on the right axis).}

cretized cases (3-18 layers) the density at the surface of the solid rises to $800 \mathrm{~kg} /$ $\mathrm{m}^{2}$. The evaporation of water at a moisture content of $7 \%$ no longer lowers the temperature significantly (Fig. S1). Only deeper into the solid, where the density is low, is the temperature profile affected by the moisture content (Fig. 8). In short, the significance of moisture content reduces as the density increases. The density rises significantly near the exposed surface when accounting for the density profile of fibreboard. The degradation of fibreboard near the exposed surface controls ignition. It follows that the influence of moisture content reduces when accounting for the density profile of fibreboard to the point that the influence of moisture content can be neglected (Fig. S1 in the Supplementary Material).

The non-uniform density profile has negligible influence on the surface temperatures (Fig. 8), as the error of 45\% (graph not shown) between the predictions with uniform and non-uniform density stems solely from the difference in ignition times $(20 \mathrm{~s})$. Away from the ignition zone, the error is less than $10 \%$. It does have a significant effect on the peak MLR. Discretizing into 9 layers of $2 \mathrm{~mm}$ or 18 layers of $1 \mathrm{~mm}$ provides the highest increase in peak MLR, as the highest density, which is in the exterior, is captured better (Fig. 9 and Fig. S4). The mass loss rate then increases by $12 \%$ under constant irradiation when introducing 18 layers compared to a uniform density. However, there is only $0.33 \mathrm{~g} / \mathrm{m}^{2}$-s difference between 9 and 

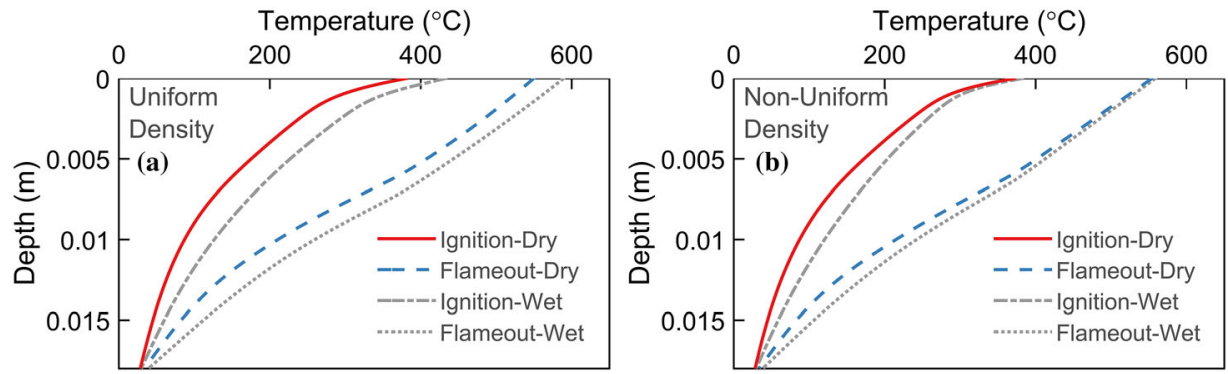

\section{Figure 8. Predicted temperature profiles of the experiments at constant irradiation. The temperafure profiles are displayed at two different times: the temperature at ignition (ignition), and the temperature at flameout (flameout). a The simulation with a uniform density with and without a drying step. b The simulation with a non- uniform density with and without a drying step.}

18 layers. Nine layers is therefore considered a good representation of the density profile of MDF. The increase in mass loss rate by $9 \%$ for 9 layers and $12 \%$ for 18 layers is in good agreement with Zeinali et al. [46]. In an independent study, published during the review of this paper, they found that simulations of the heat release rate of MDF in a corner test increases by $20 \%$ when taking into account the non-uniform density. The mass loss rate and heat release rate are related by the heat of combustion, which can be considered constant, meaning that these two studies agree well. This holds in particular if one considers the different scales. These findings also agree with Agarwal et al. [22] and Huang et al. [19], who have previously stated the importance of the density profile in replicating mass loss rate curves under constant irradiation. Our analysis proves their hypothesis, expanding it to transient irradiation, and adds to their findings.

\section{Conclusion}

This work studied the pilot ignition and extinction of fibreboard under transient irradiation, both experimentally and computationally. Experimentally, we found the mass loss rates and surface temperature of fibreboard under transient irradiation at ignition to be of the same order of magnitude as under constant irradiation. This suggests a similar ignition behaviour between fibreboard and wood. At flameout, however, MDF was shown to either undergo either extinction, transition to unsustained smouldering, or transition to sustained smouldering. These three different mechanisms lead to large variations (one order of magnitude) in the reported mass loss rate, and a variation of $150^{\circ} \mathrm{C}$ in surface temperature at flameout.

Computationally, this work tested the significance of the density profile on ignition. The model uses literature and measured values for chemical and thermal parameters. We compared the predictions using a uniform density to using nonuniform density profiles. Firstly, our results showed that the influence of moisture 

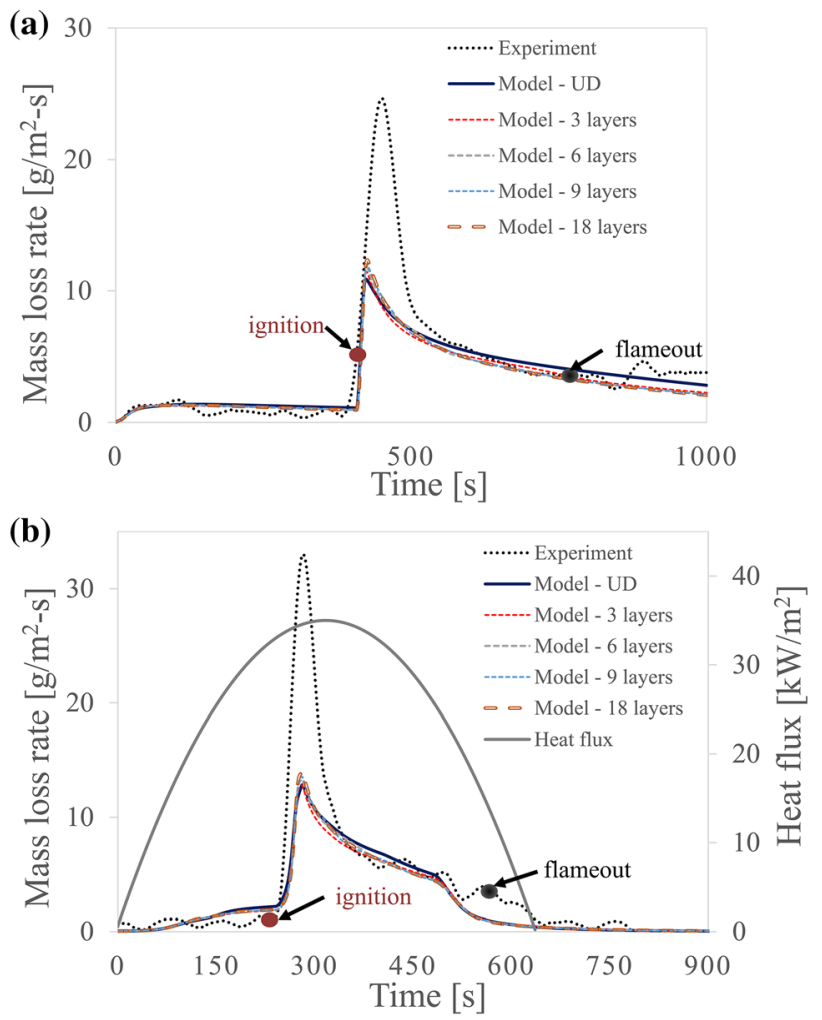

Figure 9. MLR experiments (dashed line) and model predictions (solid and dashed lines) for the constant irradiation scenario (top) and the scenario with a peak irradiation of $30 \mathrm{~kW} / \mathrm{m}^{2}$ reached at $320 \mathrm{~s}$ (botfom): the influence of a non-uniform density profile with various levels of discretization.

content changes with density profile, as the value of moisture content influenced the predictions when employing a uniform density profile but less when employing non-uniform profile. From these results, we conclude that the density profile is a more significant variable than moisture content in engineered timber. Secondly, we found that the temperature profile is unaffected by the density profile away from the ignition time with an error of less than $10 \%$. Thirdly, we found that the mass loss rate changes by up to $12 \%$ when considering a non-uniform density profile. Therefore, the predicted heat release rate and ignition behaviour based on the critical mass loss rate is affected by the density. We conclude that the non-uniform density profile of fibreboard is important to account in the modelling of ignition.

Overall, this study contributes to the literature by showing the significance of the density profile in modelling the fire behaviour of engineered wood, that the complexity of wood ignition and extinction is unlikely to be captured by a single criteria, and that flameout is a complex mechanism that can lead to either extinc- 
tion or smouldering combustion. This study is therefore a step to unravel the ignition and burning behaviour of fibreboard.

\section{Acknowledgements}

The authors thank FM Global and EPSRC (EP/M506345/1) for funding this project, and Dr. Gaurav Agarwal for his help in conducting the experiments at FM Global. Furthermore, we would like to thank Han Yuan (Imperial College London) and Prof. Nieves Fernandez-Anez (Western Norway University of Applied Science) for their helpful comments.

\section{Open Access}

This article is licensed under a Creative Commons Attribution 4.0 International License, which permits use, sharing, adaptation, distribution and reproduction in any medium or format, as long as you give appropriate credit to the original author(s) and the source, provide a link to the Creative Commons licence, and indicate if changes were made. The images or other third party material in this article are included in the article's Creative Commons licence, unless indicated otherwise in a credit line to the material. If material is not included in the article's Creative Commons licence and your intended use is not permitted by statutory regulation or exceeds the permitted use, you will need to obtain permission directly from the copyright holder. To view a copy of this licence, visit http://creat ivecommons.org/licenses/by $/ 4.0 /$.

\section{ELECTRONIC SUPPLEMENTARY MATERIAL}

The online version of this article (https://doi.org/10.1007/s10694-020-01017-6) contains supplementary material, which is available to authorized users.

\section{References}

1. Küppers J, Zehfuß J, Steeger F, Kampmeier B (2016) Fire safety of ETICS with wood fibreboards for multi-storey buildings first research and development results. In: MATEC web of conferences, vol 46, pp 1-11

2. Smulski S (1997) Engineered wood products: a guide for specifiers, designers and users. Plywood Fabricator Service Research Foundation

3. Emmons HW, Atreya A (1982) The science of wood combustion. Proc Indian Acad Sci Sect C Eng Sci 5:259268. https://doi.org/10.1007/BF02904581

4. Atreya A (1983) Pyrolysis, ignition and fire spread on horizontal surfaces of wood. Harvard University, Cambridge

5. Atreya A, Abu-Zaid M (1991) Effect of environmental variables on piloted ignition. In: Fire safety science - proceedings of the third international symposium, pp 177-186 
6. Boonmee N, Quintiere JG (2002) Glowing and flaming autoignition of wood. Proc Combust Inst 29:289296. https://doi.org/10.1016/S1540-7489(02)80039-6

7. Boonmee N, Quintiere JG (2005) Glowing ignition of wood: the onset of surface combustion. Proc Combust Inst 30:23032310. https://doi.org/10.1016/j.proci.2004.07.022

8. Spearpoint MJ, Quintiere JG (2000) Predicting the burning of wood using an integral model. Combust Flame 123:308325. https://doi.org/10.1016/S0010-2180(00)00162-0

9. Park WC, Atreya A, Baum HR (2010) Experimental and theoretical investigation of heat and mass transfer processes during wood pyrolysis. Combust Flame 157:481494. https://doi.org/10.1016/j.combustflame.2009.10.006

10. Richter F, Atreya A, Kotsovinos P, Rein G (2019) The effect of chemical composition on the charring of wood across scales. Proc Combust Inst 37(3):4053-4061

11. Emberley R, Inghelbrecht A, Yu Z, Torero JL (2017) Self-extinction of timber. Proc Combust Inst 36:30553062. https://doi.org/10.1016/j.proci.2016.07.077

12. Bartlett AI, Hadden RM, Hidalgo JP et al (2017) Auto-extinction of engineered timber: Application to compartment fires with exposed timber surfaces. Fire Saf J. https://doi.o $\mathrm{rg} / 10.1016 / \mathrm{j}$.firesaf.2017.03.050

13. Wasan SR, Van Hees P, Merci B (2010) Study of pyrolysis and upward flame spread on charring materials. Part I: Experimental study. Fire Mater 35:209-229

14. Wasan SR, Rauwoens P, Vierendeels J, Merci B (2011) Study of vertical upward flame spread on charring materials. Part II: Numerical simulations. Fire Mater 35:261-273

15. Li KY, Fleischmann CM, Spearpoint MJ (2013) Determining thermal physical properties of pyrolyzing New Zealand medium density fibreboard (MDF). Chem Eng Sci 95:211220. https://doi.org/10.1016/j.ces.2013.03.019

16. Li K, Pau D, Hou Y, Ji J (2014) Modeling pyrolysis of charring materials: determining kinetic properties and heat of pyrolysis of medium density fiberboard. Ind Eng Chem Res 53:141-149

17. Li K, Huang X, Fleischmann C et al (2014) Pyrolysis of medium density fibreboard: optimized search for kinetic scheme and parameters via genetic algorithm driven by Kissingers method. Energy Fuels. https://doi.org/10.1021/ef501380c

18. Li K, Pau D, Wang J, Ji J (2015) Modelling pyrolysis of charring materials: determining flame irradiation using bench-scale experiments of medium density fibreboard (MDF). Chem Eng Sci 123:39-48

19. Huang X, Li K, Zhang $\mathrm{H}$ (2017) Modelling bench-scale fire on engineered wood: Effects of transient flame and physicochemical properties. Proc Combust Inst 36:31673175. https://doi.org/10.1016/j.proci.2016.06.109

20. Zhao G, Beji T, Zeinali D et al (2017) Numerical study on the influence of in-depth radiation in the pyrolysis of medium density fibreboard. In: 15th international conference fire and materials, pp 863877

21. Girods P, Bal H, Biteau H et al (2011) Comparison of pyrolysis behavior results between the cone calorimeter and the fire propagation apparatus heat sources. Fire Saf Sci

22. Argawal G, Chaos M, Wang Y, Zeinali D (2016) Pyrolysis model properties of engineered wood products and validation using transient heating scenarios. Interflam

23. DiDomizio M, Mulherin P, Weckman E (2016) Ignition of wood under time-varying radiant exposures. Fire Saf J 82:131-144

24. Vermesi I, DiDomizio MJ, Richter F, Weckman E, Rein G (2017) Pyrolysis and spontaneous ignition of wood under transient irradiation: experiments and a-priori predictions. Fire Saf J 91:218225. https://doi.org/10.1016/j.firesaf.2017.03.081

25. Santamaria S, Hadden, RM (2019) Experimental analysis of the pyrolysis of solids exposed to transient irradiation. Applications to ignition criteria. Proceedings of the 
Combustion Institute. Elsevier Inc., 37(3), pp 42214229. https://doi.org/10.1016/j.proci.2 018.05 .104

26. Gong T, Xie Q, Huang X (2018) Fire behaviors of flame-retardant cables part I: decomposition, swelling and spontaneous ignition. Fire Saf J 95(2017):113121. https://d oi.org/10.1016/j.firesaf.2017.10.005

27. Zhai $\mathrm{C}$ et al (2017) Pyrolysis and spontaneous ignition of wood under time-dependent heat flux. J Anal Appl Pyrol 125:100108. https://doi.org/10.1016/j.jaap.2017.04.013

28. Gong $\mathbf{J}$ et al (2019) Analytical prediction of pyrolysis and ignition time of translucent fuel considering both time-dependent heat flux and in-depth absorption. Fuel 235(2018):913922. https://doi.org/10.1016/j.fuel.2018.08.042

29. Vermesi I, Roenner N, Pironi P et al (2015) Pyrolysis and ignition of a polymer by transient irradiation. Combust Flame 000:111. https://doi.org/10.1016/j.combustflame.2 015.08 .006

30. Simms DL, Law M (1967) The ignition of wet and dry wood by radiation. Combust Flame 11:377388. https://doi.org/10.1016/0010-2180(67)90058-2D

31. Vermesi I, Rein G (2016) One-dimensional model of pyrolysis and ignition of medium density fiberboard subjected to transient irradiation. Fire Evacuation Model Tech Conf

32. Carvel R, Steinhaus T, Rein G, Torero JL (2011) Determination of the flammability properties of polymeric materials: a novel method. Polym Degrad Stab 96:314-319

33. Chaos M, Khan MM, Dorofeev SB (2013) Pyrolysis of corrugated cardboard in inert and oxidative environments. Proc Combust Inst 34:25832590. https://doi.org/10.1016/j.p roci.2012.06.031

34. Chaos M (2014) Spectral aspects of bench-scale flammability testing: application to hardwood pyrolysis. Fire Saf Sci 11:165178. https://doi.org/10.3801/IAFSS.FSS.11-165

35. Khan M, De Ris J, Ogden S (2008) Effect of moisture on ignition time of cellulosic materials. Fire Saf Sci 9:167-178

36. Reszka P (2008) In-Depth Temperature Profiles in Pyrolyzing Wood. University of Edinburgh

37. Lautenberger C, Fernandez-Pello C (2009) Generalized pyrolysis model for combustible solids. Fire Saf J 44:819-839

38. Boulet P, Parent G, Acem Z, Rogaume T, Fateh T, Zaida J, Richard F (2012) Characterization of the radiative exchanges when using a cone calorimeter for the study of the plywood pyrolysis. Fire Saf J 51:53-60

39. Richter F, Rein G (2020) A multiscale model of wood pyrolysis to study the role of chemistry and heat transfer at the mesoscale. Combust Flame 216:316325. https://doi.or g/10.1016/j.combustflame.2020.02.029

40. Richter F, Rein G (2019) Heterogeneous kinetics of timber charring at the microscale. J Anal Appl Pyrolysis 138:19. https://doi.org/10.1016/j.jaap.2018.11.019

41. Lautenberger C, Fernandez-Pello C (2009) A model for the oxidative pyrolysis of wood. Combust Flame 156:1503-1513

42. European Aluminium Association (1994) Aluminium: Physical properties, characterisitics and alloys. Technical Report. Banbury, UK

43. Delichatsios M (2005) Piloted ignition times, critical irradiationes and mass loss rates at reduced oxygen atmospheres. Fire Saf J 40:197-212

44. McAllister S (2013) Critical mass flux for flaming ignition of wet wood. Fire Saf J 61:200-206

45. Babrauskas V (2003) Common solids. In: Ignition handbook, ch. 7. Fire Science Publishers, pp 234-251

46. Zeinali D, Gupta A, Maragkos G, Agarwal G, Beji T, Chaos M, Wang Y, Degroote J, Merci B, Division MS, Livermore L, Avenue E, Box PO (2019) Study of the impor- 
tance of non-uniform mass density in numerical simulations of fire spread over MDF panels in a corner configuration. Combust Flame https://doi.org/10.1016/j.combustflam e.2018.11.020

Publisher's Note Springer Nature remains neutral with regard to jurisdictional claims in published maps and institutional affiliations. 